\title{
ANÁLISE DA CULTURA DE PREVENÇÃO E PERCEPÇÃO DE RISCO DE INCÊNDIO EM COMUNIDADES ESCOLARES DE PORTO ALEGRE PARA O DESENVOLVIMENTO DE TREINAMENTO PARA PROFESSORES
}

\author{
Ângela Gaio Graeff ${ }^{1}$ \\ Raquel da Silva Rodrigues ${ }^{2}$
}

\begin{abstract}
RESUMO
O trabalho descreve uma pesquisa realizada em duas escolas públicas do município de Porto Alegre/RS com o objetivo de mapear a percepção de risco de incêndio das duas comunidades escolares para o desenvolvimento de um treinamento para os professores das escolas, para que os mesmos possam atuar como multiplicadores de conhecimento sobre segurança contra incêndio. $O$ trabalho tem como justificativa o incêndio na Boate Kiss, Santa Maria/RS, que teve 242 vítimas em 2013. Desde então, leis foram criadas para tornar mais rígida a fiscalização no Estado, mas pouca coisa foi feita em relação ao conhecimento da população, dos usuários que precisam ser treinados e instruídos sobre o que fazer em situações de risco. Sendo assim, é vista uma necessidade de medidas que trabalhem a cultura de prevenção contra incêndio da sociedade, pois, mesmo 6 anos após a tragédia na boate, existe uma grande falha na educação em segurança contra incêndio no Estado do Rio Grande do Sul. Todas as atividades foram elaboradas, promovidas e aplicadas pelo projeto "Educar para Prevenir: segurança contra incêndio nas escolas", um projeto de extensão da Universidade Federal do Rio Grande do Sul (UFRGS).
\end{abstract}

Palavras-chave: Segurança contra incêndio. Cultura de prevenção. Percepção de risco. Ensino. Treinamento.

\footnotetext{
1 Professora da Universidade Federal do Rio Grande do Sul - UFRGS, Departamento de PósGraduação em Engenharia Civil.

${ }^{2}$ Acadêmica da Universidade Federal do Rio Grande do Sul - UFRGS
} 


\section{ANALYSIS OF FIRE RISK PREVENTION AND PERCEPTION CULTURE IN PORTO ALEGRE SCHOOL COMMUNITIES FOR TEACHING TRAINING DEVELOPMENT}

The work describes a research carried out in two public schools of Porto Alegre / RS aiming to map the perception of fire risk of two school communities for the development of training for schoolteachers, so that they can operate as multipliers of fire safety know ledge. The work justification is the Kiss Club fire, Santa Maria / RS, which had 242 victims in 2013. Since then, times have been caused by tightening the state inspection, but little has been done regarding know ledge of the population, users who need to be trained and educate don what to do in risk situations. Therefore, a measure of action is needed that works the society's fire prevention culture, because even 6 year safter the Kiss Club tragedy, there is a major failure in fire safety education in the state of Rio Grande do Sul. The activities were designed, promoted and implemented by the project "Educate to Prevent: Fire Safety in Schools", an extension project of the Federal University of Rio Grande do Sul (UFRGS).

Keywords: FireSafety. Preventionculture. Riskperception. Teaching. Training.

\section{INTRODUÇÃO}

A sociedade brasileira, assim como em grande parte do mundo, tem a tendência de reagir a tragédias e não de se prevenir contra elas. Por isso, no Brasil, um dos Estados mais desenvolvidos na área da segurança contra incêndio é São Paulo (SP), que teve dois dos incêndios mais notórios do país. Em 1972, o incêndio no Edifício Andraus, deixou 16 pessoas mortas e 300 pessoas foram resgatadas. Dois anos depois, o incêndio no Edifício Joelma deixou 187 mortos e mais de 300 feridos.

Mesmo com incêndios tão próximos, o Estado do Rio Grande do Sul (RS) precisou passar por incêndios no seu território para começar a desenvolver de forma mais rígida, uma legislação e sua consequente conscientização na área da 
segurança contra incêndio. Em 27 de Abril de 1976, o incêndio nas Lojas Renner em Porto Alegre (RS) marcava o primeiro grande incêndio do Estado do Rio Grande do Sul, deixando 41 pessoas mortas. Até então, Porto Alegre (RS) não possuía nenhuma lei que regulamentasse qualquer medida de prevenção, proteção ou combate a incêndios. Embora alguns decretos tenham sido divulgados, a primeira Lei a nível Estadual foi criada dois anos após o incêndio no Cine Cacique (Porto Alegre, RS), em 1997, que não deixou feridos. A Lei Complementar Municipal no 420, criada em 1998 no Município de Porto Alegre, foi substituída 15 anos depois pela Lei Complementar Estadual 14.376, também conhecida como Lei Kiss Estadual. A Lei Kiss foi sancionada pelo então governador, Tarso Genro, 11 meses depois da tragédia que ocorreu em Santa Maria/RS, no dia 27 de janeiro de 2013, que deixou 242 mortos, sendo essa a segunda maior tragédia em número de mortos com incêndios no Brasil.

Após a tragédia da Boate Kiss em Santa Maria, houve uma mudança de paradigma na área da segurança contra incêndios: a fiscalização ficou mais rígida, principalmente em locais de reunião de público, e a elaboração do PPCI (Plano de Proteção e Prevenção contra Incêndio) passou a adotar critérios que se assemelham à legislação do estado de São Paulo, que é considerada uma referência no País.

Mesmo com diversas mudanças e avanços na área, à medida que o tempo passa e a tragédia na Boate Kiss se distancia, a preocupação da população em relação à segurança contra incêndio também diminui.

Inserido neste cenário, onde a comoção na sociedade é muito forte logo que uma tragédia ocorre e tende a ser esquecida ao longo dos anos, é que surgiu o Projeto Educar para Prevenir: segurança contra incêndio nas escolas, um Projeto de extensão da UFRGS que tem por objetivo entregar para a sociedade métodos que auxiliem na disseminação e consolidação de uma cultura de segurança contra incêndio por meio do conhecimento da percepção de risco de forma experimental em duas comunidades escolares de Porto Alegre/RS.

Analisar a percepção de risco das comunidades é um fator importante para o entendimento do nível de conhecimento das mesmas, para assim, melhor desenvolver medidas e formações que traduzam os conhecimentos básicos da área 
da segurança contra incêndio para as comunidades escolares. Sendo assim, analisar a percepção de risco dessas comunidades escolares, bem como a proposta de medidas que melhorem a cultura na área da segurança contra incêndio nestas escolas e em outras onde o método poderá ser replicado, compreendem a proposta deste trabalho.

\section{CONCEITUALIZAÇÃO DA PESQUISA}

Nos itens a seguir são definidos os termos que embasaram o método de pesquisa para a análise da cultura de prevenção de incêndios e percepção de risco de incêndio em comunidades escolares de Porto Alegre, por meio do desenvolvimento de treinamento para professores. $O$ correto entendimento dos termos "percepção de risco" e "cultura de segurança",foram imprescindíveis tanto para o desenvolvimento das etapas da pesquisa, quanto para a definição de como ela seria aplicada.

\subsection{Percepção}

O autor Jean-Paul Sartre (2007), citado por Poffo (2011), definiu a percepção de forma clara e objetiva dizendo: "não basta afirmar que esta mesa existe, mas sim que ela existe para mim". Definindo a percepção com essas palavras, pode-se observar dois pontos importantes sobre a palavra: ela é individual e subjetiva, ou seja, cada indivíduo desenvolverá a sua própria percepção. E, segundo, uma mesa ou qualquer outro objeto, passa a existir para um indivíduo quando este indivíduo repara na sua existência, quando esta mesa ganha um significado. Refletindo sobre essa definição para os fins deste trabalho, pode-se comparar a mesa utilizada pelo autor, com as medidas de prevenção contra incêndios, que só serão percebidas pelos indivíduos quando os mesmos atribuírem à elas um significado. Significado este, que só será obtido quando houver medidas que trabalhem a educação do mesmo. 


\subsubsection{Percepção de risco}

O termo percepção de risco surgiu em 1960 em função de a opinião pública ter sido contra a implantação da tecnologia nuclear que era considerada pelos cientistas como uma energia limpa. As comunidades científicas e governamentais não entendiam porque a percepção do público foi contra o uso da energia nuclear quando todos os cientistas declararam o quão seguro era a nova tecnologia. $O$ primeiro estudo sobre Percepção de Riscos foi desenvolvido em 1969 por Chauncey Starr intitulado "Social benefit versus technologicalrisk" que investigou detalhadamente os riscos e identificou que a sociedade parecia aceitar riscos na medida em que eles estavam associados com os benefícios (SILVA E FRANÇA, 2011). Ou seja, à medida que a sociedade se vê beneficiada, ela tende a ter uma maior aceitação ao risco e ao que ele pode causar.

Poffo (2011) define a percepção de risco como o processo de organizar e interpretar dados sensoriais recebidos pelas pessoas, diante de um possível evento perigoso, imprevisto ou provável, o qual pode prejudicar os seres humanos, os recursos naturais, a fauna e flora e os bens materiais. Definindo assim, a percepção de risco como sendo algo individual, formado pelas experiências de cada um. Logo, essa percepção pode ser melhorada se existirem medidas que trabalhem o tema da percepção, como, por exemplo, percepção de risco de incêndio. Educar e treinar acerca de algum risco, para o tornar parte das experiências pessoas de um indivíduo, melhorando assim, a sua percepção.

Duarte (2002), esclarece que a percepção ao risco pela sociedade muda com a educação, a qualidade de vida e a introdução de novas tecnologias. Os estudos científicos têm identificado os riscos cada vez mais cedo do que no passado e a divulgação dos mesmos pela imprensa tem sido mais visível e intensa, criando imagens dramáticas de desastres. 


\subsection{Cultura de segurança}

O conceito de cultura de segurança relaciona-se com a sensibilização, conscientização e participação ativa dos cidadãos na sociedade, promovendo as medidas de autoproteção, convertendo-os assim, no primeiro agente de proteção civil. A sua atuação pode efetivar-se em diversos cenários, tanto na escola, como em casa, no local de trabalho, na comunidade ou no bairro onde vivem (MACHADO, 2012).

A cultura de segurança não se baseia apenas em medidas técnicas, uma vez que, para que estas medidas sejam eficazes, os usuários precisam ter uma percepção de risco adequada para entender o significado de todas as medidas de segurança, por exemplo, em uma edificação. Não basta ter presentes em uma edificação extintores e planos de abandono se os usuários que utilizam essa edificação não sabem o que cada uma dessas medidas significa.

Para Seito et al. (2008), engajar toda a população na prevenção contra incêndio com campanhas de treinamento em escolas e veículos de comunicações é um instrumento que o país pode ativar. De acordo com os autores, “...é triste vermos crianças e indivíduos deformados por queimaduras que poderiam ter sido evitadas com procedimentos simples de segurança”.

Para que haja uma efetiva cultura de segurança contra incêndio, é preciso que haja treinamento em todos os níveis de educação, ensinando desde as crianças mais novas até os adultos, nos seus locais de trabalho, sobre o que fazer em caso de incêndio. Porém, as medidas de forma isolada e sem contexto não irão gerar uma sensibilização na população, por isso, além de mostrar quais ações devem ser tomadas em caso de incêndio, devemos ensinar à população sobre o que já aconteceu e o que pode acontecer caso não tenhamos os conhecimentos necessários na área da segurança contra incêndio. Desta forma, com medidas educativas em conjunto com a sensibilização e projetos adequados (como o Plano de Proteção e Prevenção contra Incêndio), podemos consolidar uma cultura de segurança contra incêndio. 


\subsection{Medidas de prevenção contra incêndio no Brasil e no mundo}

A área da segurança contra incêndio no Brasil está em fase de desenvolvimento e, por isso, ainda não temos no país campanhas de prevenção contra incêndio fortemente implementadas, como existem em países mais desenvolvidos nesta área, onde já se tem inserida na sociedade uma cultura de prevenção contra incêndios.

Nos Estados Unidos, existe a forte atuação da NFPA (National Fire Protection Association), que através dos Códigos Nacionais Contra Incêndios, faz o desenvolvimento profissional, educação, programas de assistência às comunidades e investigação. Além disso, a Associação dispõe de um vasto número de atividades para serem desenvolvidas com crianças nas escolas, na chamada "FirePrevention Week". Além da Associação, há uma cultura muito forte do uso de detectores de fumaça nas residências unifamiliares.

No Brasil, temos acesso aos materiais disponíveis pela NFPA em Português e em Espanhol, porém, não temos a aplicação destes materiais de popularização dos conhecimentos sobre segurança contra incêndio nas escolas para crianças e adolescentes. Em 2009, a Fundação para o desenvolvimento da educação, do Estado de São Paulo, desenvolveu um Manual de orientação à prevenção e combate a incêndio nas escolas, com o objetivo de orientar as escolas sobre noções técnicas acerca da ocorrência de um incêndio entre outras informações básicas. No Estado do Paraná/PR, a Secretaria de Estado da Educação e da Casa Militar da Governadoria, criou o Programa Brigadas Escolares, que visava promover a conscientização e a capacitação da Comunidade Escolar do Estado do Paraná, para ações de eventos danosos, naturais ou antropogênicos.

Mesmo havendo algumas medidas de prevenção no Brasil, estas ocorrem dentro de cada um dos Estados, sem haver um Programa Nacional de Prevenção contra Incêndio para a população. No Estado do Rio Grande do Sul, depois do incêndio na Boate Kiss em Janeiro de 2013, a legislação passou a ser mais rígida, mas não foram desenvolvidas medidas que trabalhassem a cultura de prevenção contra incêndio na sociedade. Seguindo o pensamento de Jean-Paul Sartre (2007) 
na sua definição de percepção, melhorar apenas as medidas que devem ser adotadas em uma edificação e tornar mais rígida a legislação, de nada adianta, pois os usuários dessas edificações não entendem essas medidas, logo, essas medidas não existem para os usuários. Por isso, em uma situação de incêndio, as chances desses usuários não utilizarem as medidas presentes nas edificações para extinguir o fogo ou não permitir que ele avance, podem ser despercebidas, pois não foram ensinados a entender essas medidas.

\section{MÉTODO DE PESQUISA}

Para entender a percepção de risco, em caráter experimental, de duas comunidades escolares do município de Porto Alegre/RS, e a partir disto, guiar o desenvolvimento de ferramentas para a disseminação e consolidação de uma cultura de segurança contra incêndio nas mesmas, o Projeto Educar para Prevenir foi dividido em quatro etapas, explicadas de acordo com a Figura 1, que contemplam os objetivos traçados.

Figura 1 - Etapas de desenvolvimento do Projeto Educar para Prevenir.

\begin{tabular}{|c|c|c|c|}
\hline Etapa 1 & Etapa 2 & Etapa 3 & Etapa 4 \\
\hline $\begin{array}{l}\text { Organização interna } \\
\text { do projeto e } \\
\text { primeiro contato com } \\
\text { as escolas } \\
\text { selecionadas para } \\
\text { explicação dos } \\
\text { objetivos e métodos } \\
\text { do projeto. }\end{array}$ & $\begin{array}{l}\text { Aplicação de } \\
\text { questionários para } \\
\text { entender a } \\
\text { percepção de risco } \\
\text { das duas } \\
\text { comunidades } \\
\text { escolares } \\
\text { participantes. Os } \\
\text { questionários foram } \\
\text { divididos em } 5 \text { tipos, } \\
\text { sendo diferentes } \\
\text { entre si no nível de } \\
\text { dificuldade e na } \\
\text { faixa etária que } \\
\text { seriam aplicados. }\end{array}$ & $\begin{array}{c}\text { Análise dos } \\
\text { resultados da } \\
\text { pesquisa para o } \\
\text { mapeamento das } \\
\text { maiores deficiências } \\
\text { acerca do } \\
\text { conhecimento dos } \\
\text { alunos, professores, } \\
\text { pais e responsáveis } \\
\text { sobre segurança } \\
\text { contra incêndio. A } \\
\text { partir dessa análise } \\
\text { da percepção de } \\
\text { risco, desenvolver a } \\
\text { formação para os } \\
\text { professores e os } \\
\text { materiais } \\
\text { pedagógicos para os } \\
\text { alunos. }\end{array}$ & $\begin{array}{c}\text { Aplicação da } \\
\text { formação para os } \\
\text { professores e } \\
\text { entrega dos } \\
\text { materiais } \\
\text { pedagógicos, bem } \\
\text { como a avaliação } \\
\text { dos efeitos das } \\
\text { ferramentas } \\
\text { desenvolvidas } \\
\text { acerca da } \\
\text { percepção de risco } \\
\text { das duas } \\
\text { comunidades } \\
\text { escolares. }\end{array}$ \\
\hline
\end{tabular}

As etapas 1 e 2 já foram realizadas nas duas escolas. O Projeto se encontra na etapa 3, desenvolvendo as ferramentas para a disseminação e consolidação de uma cultura de segurança contra incêndio nessas duas escolas. São apresentados 
nos itens a seguir a análise de dois dos cinco questionários aplicados na Etapa 2 do projeto, e algumas das propostas de ação a partir do que foi analisado nos questionários (Etapa 3 do projeto).

\subsection{Escolas Participantes}

Para realizar a análise da percepção de risco para esta pesquisa, foram aplicados questionários (posteriormente descritos no item 3.2) em duas escolas do município de Porto Alegre/RS. Os questionários foram aplicados na Escola Estadual de Ensino Médio Itália (E.E.E.M.I.) e no Instituto Estadual Rio Branco (I.E.R.B.).

A E.E.E.M.I., localizada na Zona Norte de Porto Alegre, atende em torno de 750 alunos entre o Ensino Fundamental e Médio, nos turnos da manhã, tarde e noite. A Escola Itália não possui o Plano de Prevenção e Proteção contra Incêndio e teve um incêndio em 2014, onde um aluno jogou um rojão dentro do depósito de materiais de limpeza. Desde então, as medidas tomadas pela direção da escola e pelo Estado, foi a colocação de um sistema de alarme de incêndio (que alguns alunos disseram não saber se funciona), extintores de incêndio que atualmente se encontram fora da validade e sinalizações para indicar as saídas.

O I.E.R.B., localizado no Centro Histórico do município de Porto Alegre, atende em torno de 1.300 alunos entre o ensino fundamental e médio, nos turnos da manhã, tarde e noite. Em uma conversa inicial com a direção da escola, foi informado que a escola possuía $\mathrm{PPCl}$, mas ao andar pela escola foi percebida a falta de extintores de incêndio e de sinalizações ou a grande distância entre eles. Os professores não tem nenhum tipo de treinamento sobre como agir em caso de incêndio.

\subsection{Análise dos Resultados}

A pesquisa para entender a percepção de risco foi feita por meio de questionários com toda a comunidade escolar, sendo dividido em cinco tipos, de acordo com a Figura 2. 
Figura 2 - Esquema da divisão dos questionários.

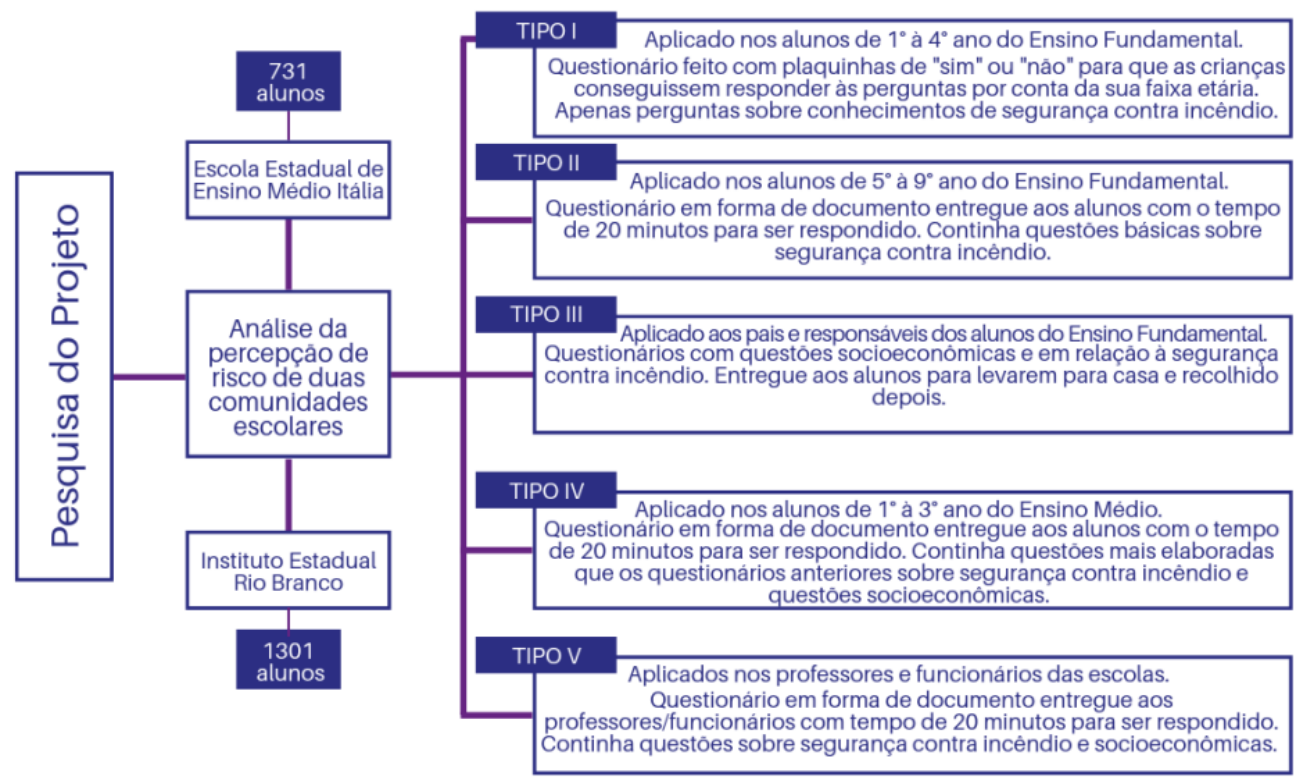

Para fins de análise de resultados para este trabalho, utilizaremos os dados dos questionários Tipo II e Tipo IV. A seguir, faremos a análise destes dois tipos de questionário separadamente, comparando alguns dos resultados das duas comunidades escolares.

\subsubsection{Análise do Questionário Tipo II}

O questionário Tipo $\mathrm{II}$, aplicado nos alunos de $5^{\circ}$ a $9^{\circ}$ ano do ensino fundamental, continha 28 questões. Todas as questões eram sobre segurança contra incêndio. Conforme a Figura 3, este questionário foi respondido por 461 alunos, 217 da Escola Estadual de Ensino Médio Itália e 244 do Instituto Estadual Rio Branco. Para a análise neste trabalho, levando em consideração o tamanho da pesquisa, foram selecionadas as questões que foram mais relevantes para 0 mapeamento da percepção de risco dos alunos. 


\section{Revista FLAMMAE}

Revista Científica do Corpo de Bombeiros Militar de Pernambuco

Vol. 05 N.14 - Edição Especial 5 CILASCl -- ISSN 2359-4829

Versão on-line disponível em: $\underline{\text { http://www.revistaflammae.com }}$

Figura 3 - Gráfico do número de alunos por escola e ano escolar.

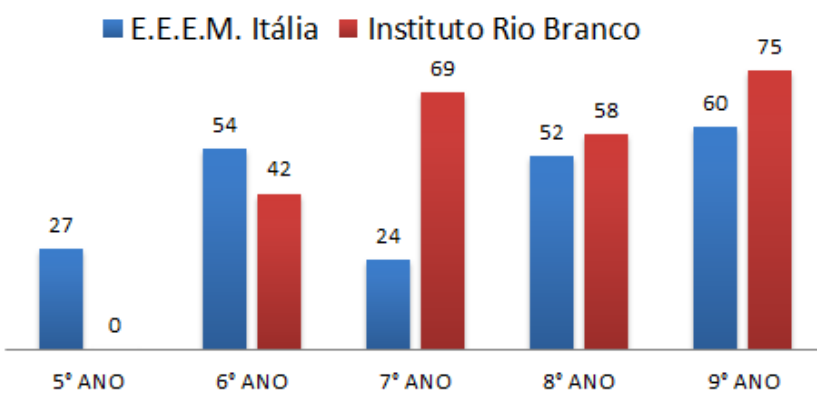

\section{Questão número 1: Como você identificaria um incêndio na sua escola?}

De acordo com a Figura 4, 52\% dos alunos responderam que identificariam um incêndio dentro da sua escola pela fumaça e $25 \%$ apenas quando vissem o fogo. Essas porcentagens demonstram a falta de treinamento dentro das escolas caso aconteça um incêndio visto que, os alunos saberiam do acontecimento apenas se enxergassem o fogo ou a fumaça.

Figura 4 - Gráfico das respostas para a questão 1
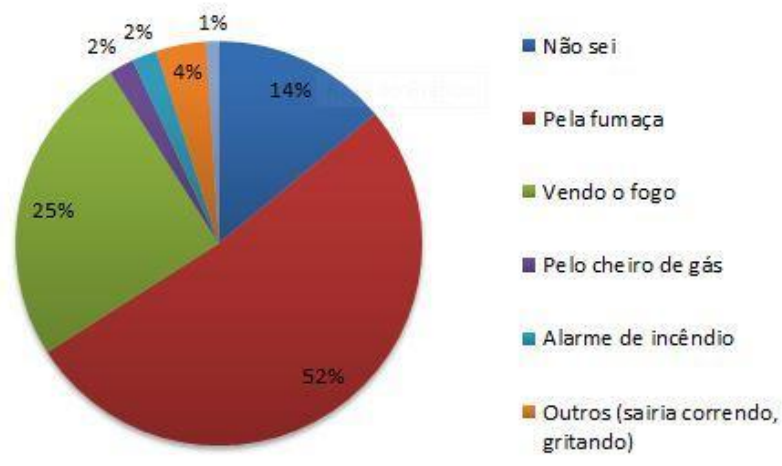

\section{Questão número 4: O que você faria caso a sua roupa pegasse fogo?}

Em relação à $4^{\text {a }}$ questão, pode-se observar na Figura 5 que $36 \%$ dos alunos bateriam na roupa para apagar o fogo e $8 \%$ correriam. Somadas, essas 
porcentagens equivalem a $44 \%$ dos alunos que responderam à questão. Salientase que além desses $44 \%$ de alunos não responderem à opção correta, que é a de "deitar e rolar no chão", indicaram opções que dariam maiores condições para o fogo permanecer.

Figura 5 - Gráfico das respostas para a questão 4.

De itar no chão
e rolar
Bater na roupa
Correr, assim o
vento apagará o
fogo.

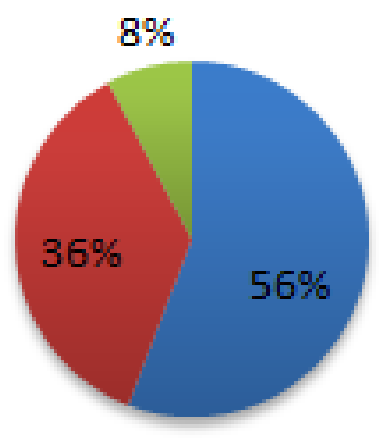

Questão número 12: Você sabe qual é o número do Corpo de Bombeiros?

De acordo com a Figura 6, que trata sobre o número de alunos que sabem o número do Corpo de Bombeiros, tem-se que $66 \%$ dos alunos dizem saber qual é o número. 
Figura 6 - Gráfico do número de alunos que responderam "sim" para as questões 12,17 e 25.

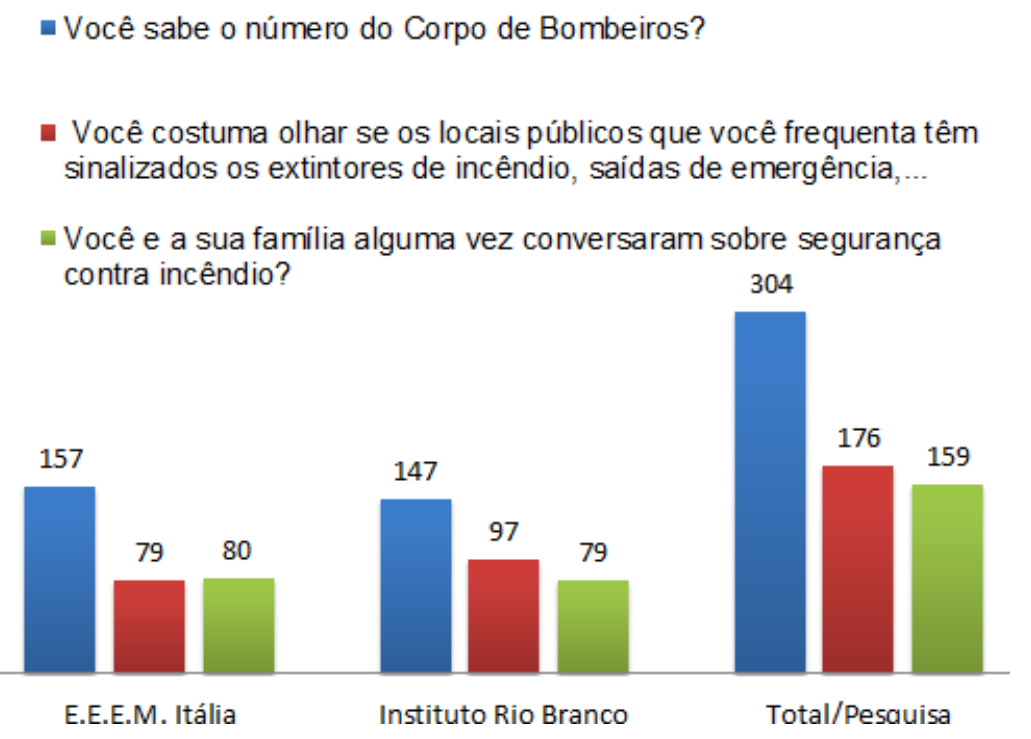

Já na Figura 7, quando perguntados sobre qual é este número, 33\% dos alunos que responderam na questão 12 que sabiam o número do Corpo de Bombeiros responderam de forma errada à pergunta.

Figura 7 - Gráfico das respostas para a questão 13 ๓ Total/Pesquisa \# Instituto Rio Branco घ E.E.E.M. Itália

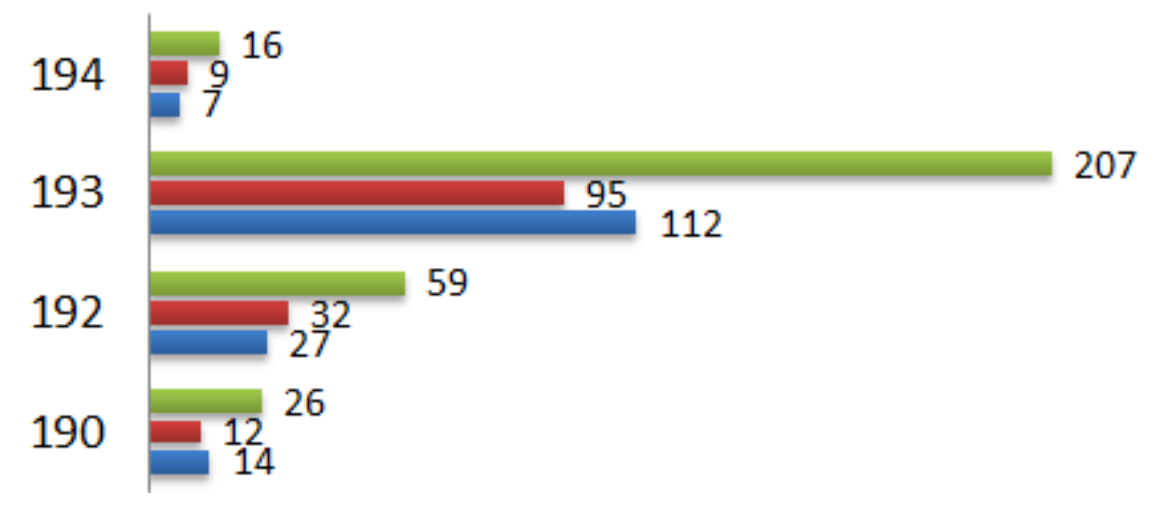


Questão número 17: Você costuma olhar se os locais públicos que você frequenta têm sinalizados os extintores de incêndio, saídas de emergência e demais medidas de segurança contra incêndio?

De acordo com a Figura 6, as porcentagens apontam a falta de cultura sobre segurança contra incêndio. Ou seja, se houvesse um treinamento apropriado, se aprenderia a observar estas sinalizações assim que se entrasse em edificações para saber o que fazer em caso de emergência.

\section{Questão número 25: Você e sua família alguma vez conversaram sobre segurança contra incêndio?}

De acordo com a Figura 7, 65\% das famílias dos alunos do Ensino Fundamental das duas escolas participantes do Projeto, nunca conversaram sobre segurança contra incêndio. Com isso, entende-se que essas famílias não sabem o que fazer caso um incêndio aconteça dentro das suas residências, mostrando como muitos habitantes de residências unifamiliares participantes desta pesquisa estão despreparados caso um incêndio aconteça.

\subsubsection{Análise do Questionário IV}

O questionário Tipo IV, aplicado nos alunos de $1^{\circ}$ a $3^{\circ}$ ano do Ensino Médio, continha 42 questões. As questões eram socioeconômicas e sobre segurança contra incêndio. Conforme a Figura 8 , este questionário foi respondido por 446 alunos, 160 da Escola Estadual de Ensino Médio Itália e 286 do Instituto Estadual Rio Branco. Para a análise da percepção de risco contra incêndio neste trabalho, levando em consideração a limitação de espaço, foram selecionadas as questões que foram mais relevantes para o mapeamento da percepção de risco dos alunos. 


\section{Revista FLAMMAE}

Revista Científica do Corpo de Bombeiros Militar de Pernambuco

Vol. 05 N.14 - Edição Especial 5 CILASCI -- ISSN 2359-4829

Versão on-line disponível em: http://www.revistaflammae.com

Figura 8 - Gráfico do número de alunos por escola e ano escolar.

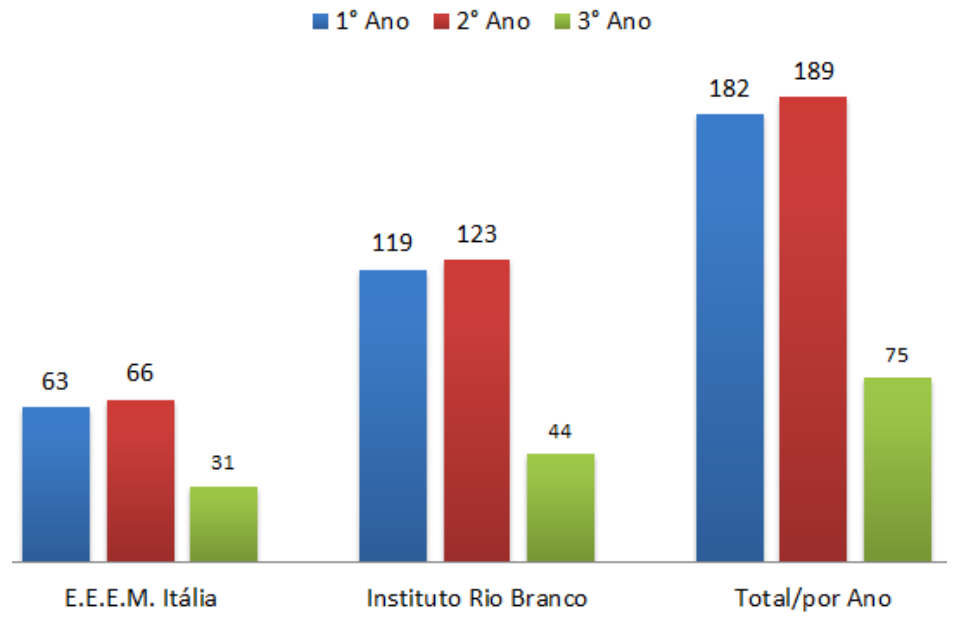

\section{Questão número 18: O que você faria se uma panela com óleo pegasse fogo} na sua casa?

A questão 18 do questionário Tipo IV, foi feita de forma dissertativa para que alternativas não influenciassem os alunos para uma resposta específica.

De acordo com a Figura 9, 57\% dos alunos apontaram opções que poderiam piorar a situação ou feri-los gravemente. Isso mostra como os alunos estão despreparados não só em questões mais específicas sobre segurança contra incêndio, mas também estão despreparados para situações que podem ocorrer no dia a dia.

Figura 9 - Gráfico das respostas para a questão 18.

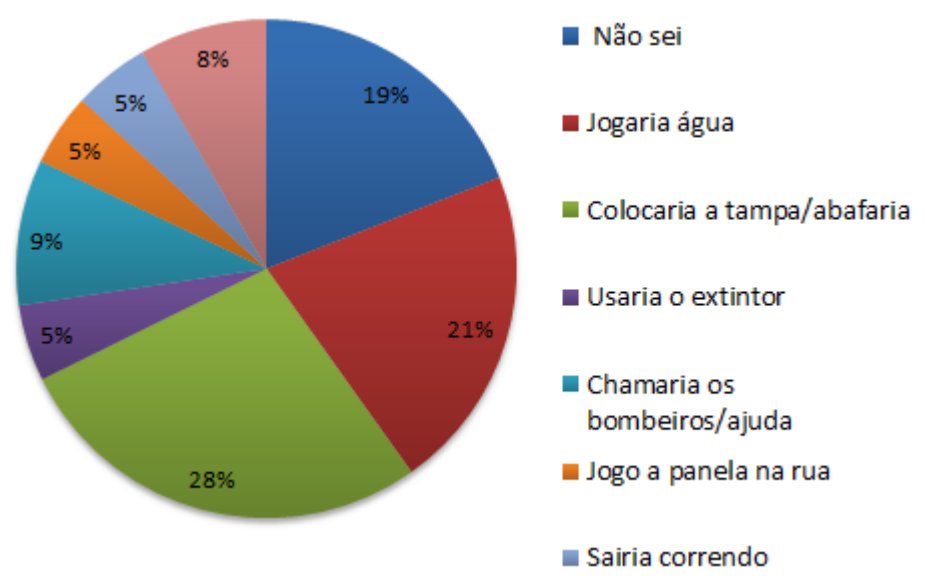




\section{Revista FLAMMAE}

Revista Científica do Corpo de Bombeiros Militar de Pernambuco

Vol. 05 N.14 - Edição Especial 5 CILASCI -- ISSN 2359-4829

Versão on-line disponível em: http://www.revistaflammae.com

Questão número 19: O que você faria se a sua roupa começasse a pegar fogo?

Em relação à questão 19, apenas $29 \%$ dos 444 alunos que responderam a essa questão apontaram a alternativa "deitar e rolar" como opção correta de ação caso a sua roupa pegasse fogo. Em outros países, como, por exemplo, nos Estados Unidos, a campanha para ensinar as crianças sobre o que fazer se a sua roupa pegar fogo é fortemente fomentada pela NFPA - National Fire Protection Association, já no Brasil, ainda temos uma grande carência de medidas educativas que melhorem as porcentagens apresentadas na Figura 10.

Figura 10 - Gráfico da questão 19.

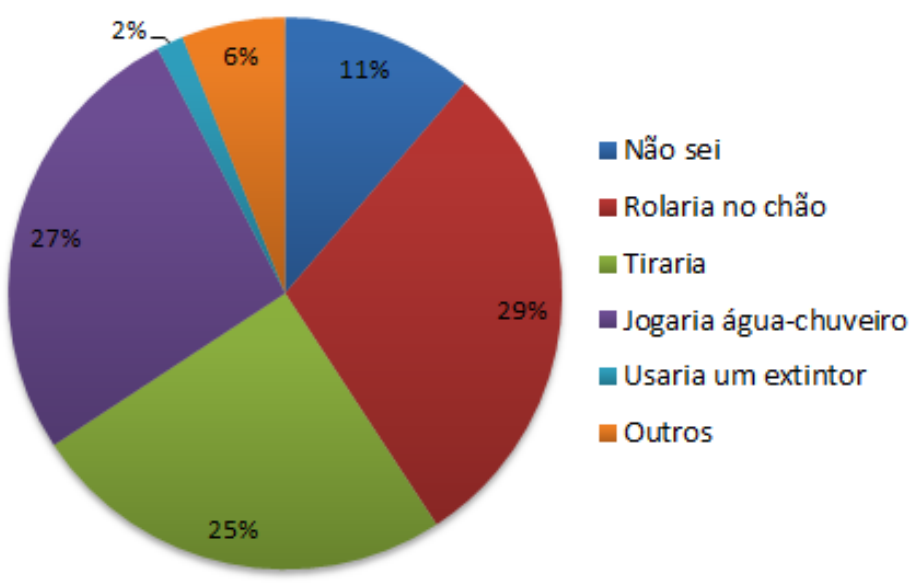

Questão número 35: Em qual local da sua escola você acha que tem mais chances de se iniciar um incêndio?

A única análise comparativa entre as duas escolas que foi obtida com uma diferençasignificativa ocorreu nessa questão. A diferença de comparação entre as duas escolas, segundo a Figura 11, foi de mais de 20\%. Em 2014 a 


\section{Revista FLAMMAE}

Revista Científica do Corpo de Bombeiros Militar de Pernambuco

Vol. 05 N.14 - Edição Especial 5 CILASCI -- ISSN 2359-4829

Versão on-line disponível em: http://www.revistaflammae.com

Escola Itália teve um incêndio causado por um aluno, que jogou um rojão dentro do depósito de materiais de limpeza. Muitos dos alunos que responderam essa pergunta estavam presentes no dia do incêndio. Levando em consideração a definição de percepção de risco (POFFO, 2011), podemos observar a maior tendência dos alunos da escola Itália a apontar o depósito de materiais de limpeza como um possível local onde pudesse ser iniciado um incêndio. Os alunos do Instituto Estadual Rio Branco não tiveram essa experiência agregada à sua percepção de risco, logo, apontaram em menor número o depósito de materiais de limpeza.

Figura 11 - Gráfico da questão 35

घ Instituto Rio Branco E.E.E.M. Itália

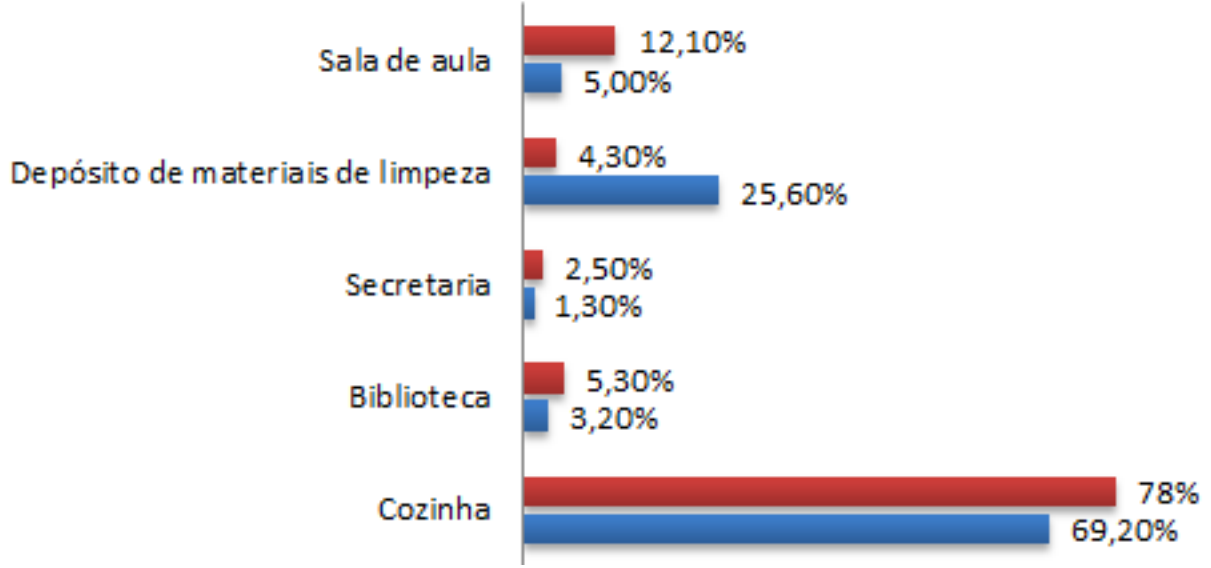

\subsection{Proposta de ferramentas pedagógicas}

De acordo com as análises apresentadas neste trabalho, o Projeto está trabalhando no desenvolvimento de ferramentas pedagógicas com o objetivo de melhorar a percepção de risco dessas duas comunidades escolares que foram analisadas. Alguns dos materiais que estão sendo desenvolvidos, e que serão apresentados em publicação posterior,é um livro que explica de forma didática para as crianças de $1^{\circ}$ a $4^{\circ}$ ano $o$ triângulo do fogo, aplicando este 


\section{Revista FLAMMAE}

Revista Científica do Corpo de Bombeiros Militar de Pernambuco

Vol. 05 N.14 - Edição Especial 5 CILASCI -- ISSN 2359-4829

Versão on-line disponível em: http://www.revistaflammae.com

conhecimento no porque devemos deitar e rolar no chão caso a roupa pegue fogo (para extinguir o fogo por abafamento). Também estão sendo desenvolvidos dois jogos de tabuleiros para trabalhar noções de evacuação de uma edificação e noções sobre equipamentos de prevenção e combate a incêndio.

\section{CONSIDERAÇÕES FINAIS}

Levando em consideração todas as análises realizadas e apresentadas neste trabalho, conclui-se que a percepção de risco das duas comunidades escolares participantes, está intimamente relacionada com as informações que se têm disponíveis sobre o assunto. A falta de conhecimento sobre o que fazer em situações do cotidiano e também em relação à segurança contra incêndio, faz-nos perceber o quanto a educação nesta área precisa ser desenvolvida. É necessário que existam medidas que trabalhem com todas as faixas etárias da sociedade brasileira conceitos básicos e detalhados sobre segurança contra incêndio, já que, segundo a pesquisa, a maior parte dos alunos não sabe sequer o número do Corpo de Bombeiros.

O objetivo do Projeto Educar para Prevenir é o de somar as medidas presentes em uma edificação com o desenvolvimento da percepção de risco da população, contribuindo assim para disseminar e consolidar uma cultura de prevenção contra incêndio, onde as pessoas que venham a ter acesso a essas informações treinem e aprendam o que deve ser feito para se prevenir, proteger ou combater um incêndio. Espera-se que as medidas que estão sendo desenvolvidas pelo projeto, em especial a formação para os professores, que está sendo realizada com base nas maiores deficiências dos conhecimentos das comunidades escolares, bem como os materiais didático-pedagógicos que visam ter como tema os aspectos menos conhecidos sobre segurança contra incêndio, contribuam para que essas duas comunidades estejam mais preparadas na área da segurança contra incêndio, tornando os professores 
multiplicadores dos conhecimentos apresentados na formação, e educando cada vez mais pessoas sobre $o$ assunto.

\section{REFERÊNCIAS}

DUARTE, Dayse. - Gerenciamento dos Riscos. 1. ed. Recife: Universidade Federal de Pernambuco, 2002.

MACHADO, A.B.M.L.M. - Percepção do risco e implementação de uma cultura de segurança: Construindo comunidades educativas resilientes. 2012. Dissertação (Mestrado em População Sociedade e Território). Instituto de Geografia e Ordenamento do Território. Universidade de Lisboa, 133 p. 2012.

FDE - Fundação para o Desenvolvimento da Educação.- Manual de orientação a prevenção e ao combate a incêndio em escolas. SP/SP: [s. n.], 2009.

PARANÁ (Estado). Governo do Estado do Paraná. Programa Brigada EscolarA Defesa Civil na Escola. Curitiba: 29 p. 2012.

POFFO, I. R. F. - Percepção de riscos e comportamento da comunidade diante deacidentes ambientais em áreas portuárias de Santos e de São Paulo. 2011. Tese de Pós-doutorado. Pontifícia Universidade Católica de São Paulo. São Paulo. 139 p. 2011.

SARTRE, Jean-Paul. O ser e o nada: ensaio de ontologia fenomenológica -. Ed. Vozes. RJ/RJ - 15 edição. 782p. 2007.

SEITO, et al. A Segurança contra incêndio no Brasil. São Paulo: Projeto Editora, 2008.

SILVA, Bernadete F. da; FRANÇA, Sergio L. B. Análise da percepção do trabalhador sobre os riscos no ambiente de trabalho: estudo de caso em unidade de operação de empresa de energia brasileira. In: VII Congresso Nacional de Excelência em Gestão, 2011, Rio de Janeiro. Artigo [...]. [S. I.: s. n.], 2011. 